\title{
Kaempferol Exhibits Progestogenic Effects in Ovariectomized Rats
}

May Fern Toh, Emma Mendonca, Sharon L. Eddie, Michael P. Endsley, Daniel D. Lantvit, Pavel A. Petukhov, and Joanna E. Burdette*

Department of Medicinal Chemistry and Pharmacognosy, College of Pharmacy, University of Illinois at Chicago, Chicago, IL 60607, USA

*Corresponding author: Joanna E. Burdette, 900 S. Ashland Street (M/C 870) Chicago, IL 60607, USA, Tel: 312-996-6153; Fax: 312-996-7107; E-mail: joannab@uic.edu

Received date: April 15, 2014, Accepted date: June 26, 2014, Published date: July 02, 2014

Copyright: (c) 2014 Toh MF, et al. This is an open-access article distributed under the terms of the Creative Commons Attribution License, which permits unrestricted use, distribution, and reproduction in any medium, provided the original author and source are credited.

\begin{abstract}
Objective: Progesterone $\left(\mathrm{P}_{4}\right)$ plays a central role in women's health. Synthetic progestins are used clinically in hormone replacement therapy (HRT), oral contraceptives, and for the treatment of endometriosis and infertility. Unfortunately, synthetic progestins are associated with side effects, including cardiovascular disease and breast cancer. Botanical dietary supplements are widely consumed for the alleviation of a variety of gynecological issues, but very few studies have characterized natural compounds in terms of their ability to bind to and activate progesterone receptors (PR). Kaempferol is a flavonoid that functions as a non-steroidal selective progesterone receptor modulator (SPRM) in vitro. This study investigated the molecular and physiological effects of kaempferol in the ovariectomized rat uteri.
\end{abstract}

Methods: Since genistein is a phytoestrogen that was previously demonstrated to increase uterine weight and proliferation, the ability of kaempferol to block genistein action in the uterus was investigated. Analyses of proliferation, steroid receptor expression, and induction of well-established PR-regulated targets Areg and Hand2 were completed using histological analysis and GPCR gene induction experiments. In addition, kaempferol in silico binding analysis was completed for PR. The activation of estrogen and androgen receptor signalling was determined in vitro.

Results: Molecular docking analysis confirmed that kaempferol adopts poses that are consistent with occupying the ligand-binding pocket of PRA. Kaempferol induced expression of PR regulated transcriptional targets in the ovariectomized rat uteri, including Hand2 and Areg. Consistent with progesterone-like activity, kaempferol attenuated genistein-induced uterine luminal epithelial proliferation without increasing uterine weight. Kaempferol signalled without down regulating PR expression in vitro and in vivo and without activating estrogen and androgen receptors.

Conclusion: Taken together, these data suggest that kaempferol is a unique natural PR modulator that activates PR signaling in vitro and in vivo without triggering PR degradation.

Keywords: Kaempferol; Progestin; Progesterone receptor; Genistein; Hormone replacement therapy; Botanicals

\section{Introduction}

Progesterone $\left(\mathrm{P}_{4}\right)$ plays an essential role in female health. The importance of $\mathrm{P}_{4}$ has led to the continued development of synthetic progesterone receptor (PR) ligands for a variety of women's health issues $[1,2]$. For example, oral contraceptives, combination hormone replacement therapy (HRT) for the treatment of menopausal symptoms, and to reduce the risk of endometrial hyperplasia and cancer associated with unopposed $\mathrm{E}_{2}$ therapy [3-5]. These common treatments contain synthetic progestins, such as medroxyprogesterone acetate (MPA), which are associated with deleterious side effects including cardiovascular disease, heart attack, stroke, and breast cancer [6,7]. Side effects are thought to occur primarily due to the promiscuous binding of synthetic progestins to other nuclear receptors such as the androgen receptor (AR), glucocorticoid receptor (GR), and mineralocorticoid receptor (MR) [8]. Therefore, the identification of progestins that have tissue and receptor specificity with minimal side effects is important.
Due to the side effects associated with HRT and the perceived safety of natural remedies, millions of menopausal women are seeking alternative therapies in the form of botanical extracts and dietary supplements [9]. Most of the formulas used to treat menopausal symptoms contain estrogenic compounds, such as genistein and 8prenyl-naringenin that bind and activate estrogen receptors. Unopposed estrogen signaling in the uterus is associated with hyperplasia and cancer [10]. $\mathrm{P}_{4}$ when combined with $\mathrm{E}_{2}$ protects against proliferation and hyperplasia of endometrial cells [11]. Therefore, botanical formulations containing both a phytoestrogen and a phytoprogestin should be safer in the uterus. Some botanicals have been identified that contain progestogenic compounds as demonstrated by in vitro and in vivo assays [12-17].

Selective PR modulators (SPRMs) are a class of PR ligands that function as an agonist, antagonist, or mixed agonist/antagonist and have clinically relevant tissue selectivity [4]. Previous studies demonstrated kaempferol is a non-steroidal phytoprogestin that functions in a cell-specific manner in vitro [13]. Kaempferol is a widely distributed dietary flavonoid found in fruits and vegetables that also has anti-oxidant and anti-inflammatory properties [18]. The antiinflammatory properties of kaempferol appear to be meditated by 
nuclear factor-kB (NFkB) [19,20]. In animal studies, kaempferol inhibited ovarian cancer tumorigenesis and angiogenesis [21,22]. Moreover, in human epidemiological studies, kaempferol intake significantly decreased (40\%) ovarian cancer incidence [21]. The biological activities demonstrated by kaempferol in these previous studies are consistent with kaempferol functioning as a progestin, especially considering progestins are known to inhibit $\mathrm{NF \kappa B}$ and are well known to protect against ovarian cancer [23-25].

The objective of this study was to investigate if kaempferol exerts progesterone-like effects in vivo using the ovariectomized SpragueDawley rat model. Since genistein is a phytoestrogen that was previously demonstrated to increase uterine weight and proliferation [3], the ability of kaempferol to block genistein action in the uterus was investigated. Analyses of proliferation, steroid receptor expression, and induction of well-established PR-regulated targets Areg and Hand 2 were completed. In addition, kaempferol in silico binding analysis was completed for PR, as was the activation of ER and AR signaling in vitro in order to determine receptor specificity. The data from this study suggest that kaempferol interacts with PR, activates the receptor without stimulating its degradation, antagonizes genisteininduced endometrial proliferation, and induces known PR target genes in vivo.

\section{Materials and Methods}

\section{Reagents}

All chemicals and reagents were purchased from Fisher (Hanover Park, IL) or Sigma-Aldrich (St. Louis, MO) unless otherwise indicated. All media for cell culture were purchased from Life Technologies, Inc (Carlsbad, CA). Fetal bovine serum (FBS) and charcoal stripped serum was purchased from Atlanta Biologicals (Norcross, GA). Genistein and kaempferol were purchased form Indofine Chemical Co. (Belle Mead, NJ) and Sigma-Aldrich (St. Louis, MO). Desmethylarzoxifen (DMA) was provided by Dr. Gregory Thatcher (Department of Medicinal Chemistry, University of Illinois at Chicago).

\section{Molecular modeling}

The crystal structure of the human PR in complex with the agonist $\mathrm{P}_{4}$ (PDB: $1 \mathrm{~A} 28 ; 1.8 \AA$ ) was used in the docking procedure [26]. The protein model was analyzed using the protein structure preparation module in MOE [27]. All ligands and water molecules were removed and hydrogen atoms were added using Protonate3D. This structure was saved as a PDB file. The 3D structures of the ligands were built and inspected with VIDA and AM1-BCC [28] partial atomic charges were calculated with Molcharge [27] and minimized using OMEGA [27]. All ligands were docked into the binding pocket of PR using GOLD (version 5.1, CCDC, Cambridge, UK) [29]. The active site was defined as all protein atoms within $6 \AA$ of $\mathrm{P}_{4}$. The scoring function used to rank the docked poses was Chem-PLP. A maximum of twenty docking solutions were generated for each structure, with early termination of the process if the respective RMSDs of the three highest ranked docking solutions were within $1.5 \AA$ RMSD of one another (GOLD default 1 setting: 100,000 Genetic Algorithm (GA) Operations, 5 islands). Flipping of ring free corners, amide bonds, protonated carboxylic acids and planar or pyramidal nitrogen atoms were allowed. MOE was also used to analyze the docking results and generate figures. The top-ranked poses were further co-minimized using MOE LigX module utilizing AMBER12HT force field for optimization and calculation of affinity score [30].

\section{Cell culture and cell lines}

Human endometrial stromal cells (HESCs) were provided by Dr. Asgerally Fazleabas (Department of Obstetrics, Gynecology, and Reproductive Biology, Michigan State University, Grand Rapids, MI). HESCs were cultured according to a previous study [29].

\section{Luciferase assay}

HESCs were grown in 12-well plates until $80 \%$ confluent. MDA-231 were grown in 12-well plates at 100,000 cells per well. Progesterone responsive element (PRE), estrogen responsive element (ERE), or prostate specific antigen (PSA) was performed as previously described and the transfection efficiency and cell viability was normalized to a co-transfected beta-galactosidase plasmid ( $\beta$-gal) [13]. Transfections preceded treatment for 24 or 48 hours. Cell lysates $(50 \mu \mathrm{L})$ were placed in 96 -well plate. The luciferase activity was quantified as previously described [29]. The results are presented as the average fold induction of treated over untreated cells (DMSO) after correcting for transfection efficiency from triplicate experiments.

\section{Western Blot Analysis}

HESC cells were incubated in serum free media with various agents for 48 hours. Cells were lysed in 1X RIPA buffer (50 mM Tris, $\mathrm{pH} 7.6$, $150 \mathrm{mM} \mathrm{NaCl}, 1 \%$ (v/v) Triton X-100, 0.1\% (w/v) SDS) and Roche protease inhibitor (Roche, Madison, WI). Protein concentrations were measured using BCA protein assay reagent (BioRad, Hercules, CA). Protein was separated by $7 \%$ SDS-PAGE and transferred onto nitrocellulose membrane. Membranes were blocked in 5\% non-fat milk in Tris-buffered saline-Tween (TBS-T-1\%). PR-A/B proteins were probed for with antibody (Santa Cruz Biotechnology, Santa Cruz, CA) in 5\% milk in TBS-T. Membranes were re-probed for actin (Cell Signaling, Danvers, MA) as loading control. Signals were detected using chemiluminescence SuperSignal West Femto Chemiluminescent Kit, (Thermo Scientific, Hanover Park, IL) according to the manufacturer's protocol on Protein Simple FluorChem E (Santa Clara, CA).

\section{Rat study}

All animal studies were approved by the UIC Animal Care and Use Committee. Sprague-Dawley ovariectomized (OVX) rats were utilized for this study to eliminate endogenous hormone production. Twentyfour animals weighing 160-180 g were purchased for the study $(n=8 /$ group) (Harlan Laboratories, Madison, WI). All rats were housed at $21^{\circ} \mathrm{C}$ in $12 \mathrm{~h}$ light: $12 \mathrm{~h}$ dark cycles and were fed $7 \%$ corn diet (Harlan Laboratories, Madison, WI) devoid of phytoestrogens. Two weeks post ovariectomy, $5.625 \mathrm{mg}$ kaempferol or genistein was dissolved in a $\mathrm{DMSO} /$ corn oil mixture and given via oral gavage daily for 8 days based on a previous study demonstrating estrogenic action of genistein at this dose and duration [3]. Control animals were given DMSO/corn oil only. Animals were sacrificed $24 \mathrm{~h}$ after the last injection.

\section{Immunohistochemistry}

Uteri were carefully excised, weighed, and fixed in $4 \%$ paraformaldehyde overnight. Histological analyses were performed according to a previously published study [31]. Primary antibodies utilized in this study included Ki67 (Abcam, Cambridge, MA), PR, ER $\alpha$ and Hand2 (Santa Cruz Biotechnology, Santa Cruz, CA) [32]. For $\mathrm{PR}, \mathrm{ER} \alpha$ and Ki67, a biotinylated horseradish peroxidase-conjugated 
anti-rabbit IgG was used as the secondary antibody (1:200, Vector, Burlingame, CA). For Hand2 detection a biotinylated horseradish peroxidase-conjugated anti-goat IgG was used as the secondary antibody (1:200, Vector, Burlingame, CA). Secondary antibody incubation was followed by $\mathrm{ABC}$ peroxidase detection enhancement (Vector, Burlingame, $\mathrm{CA}$ ) and detected by $\mathrm{DAB}$ as the chromogen (Vector, Burlingame, CA). Slides were counterstained with haemotoxylin and photomicrographs of sections were obtained using Nikon Eclipse E600 microscope. To assess proliferation in the luminal epithelial cells, a minimum of 300 cells were quantified ( 2 sections per animal) and the average taken. Data are represented as percentage of positive cells. In the stroma, the entire endometrial section was examined, and the number of proliferating stromal cells was categorized as 0 , no staining; fewer than 5, low; and more than 5, high. High, low and absent Ki67 expression was classified in endometrial stroma for all four groups.

\section{qPCR}

Uterine RNA was isolated using Trizol (Invitrogen, Carlsbad, CA) reagent as per manufacturer's instructions. The quality of total RNA was determined spectrophotometrically. Complementary DNA was made using RevertAid first strand cDNA synthesis kit (Fermentes, Glen Burnie, MD) in a total volume of $20 \mu$ l. Each real-time PCR consisted of $100 \mathrm{ng}$ cDNA, $10 \mu \mathrm{l}$ FastStart SYBR Green PCR Master Mix (Roche, Madison, WI), and $0.5 \mu \mathrm{M}$ forward and reverse primers (IDT, San Jose, CA). PCR analyses were conducted using the following set of primers; Gapdh 5'- CATGGCCTTCCGTGTTCCTA-3' (forward) and 5'-CCTGCTTCACCACCTTCTTGAT-3' (reverse), Rpl1 5'- CTGTGAGGGCATCAACATTTC-3' (forward) and 5'GTTGGTGTTCATCCGCTTTC-3' (reverse), ERa 5'AATTCTGACAATCGACGCCAG-3' (forward) and 5'GTGCTTCAACATTCTCCСТCСТC-3' (reverse), $P R \quad 5^{\prime}$ CCCGACACTTCCAGCTCTTT-3' (forward) and 5'TGTGGGATTTGCCACATGGT-3' (reverse), Hand2 5'AAGAGGAAGAAAGAGCTGAATGAGAT-3' (forward) and 5'CGTTGCTGCTCACTGTGCTT-3' (reverse), Areg 5'AACTGAACTTCTGGAGCCTTC-3' (forward) and 5'CATGCCATAGCCTAGCTGAT-3' (reverse). Fold change in mRNA expression was determined via the $\Delta \Delta \mathrm{Ct}$ method, with Gapdh as an internal control for Areg and RIP1 for Hand2, PR and ERa. Data reported are the mean fold change \pm SEM for three replicates compared to vehicle control.

\section{Statistical analysis}

All data were analyzed using one-way ANOVA, followed by Tukey's test for multiple comparisons. Statistical significance was defined as \#p $<0.05$ between groups, ${ }^{*} \mathrm{p}<0.05$ compared to control, groups not marked were not statistically different from each other.

\section{Results}

\section{Molecular modeling of kaempferol, $\mathrm{MPA}$ and $\mathrm{P}_{4}$ in PR Ligand Binding Domain (LBD)}

Kaempferol was previously reported to bind to PR, activate PREluciferase in a concentration-dependent manner, and it was antagonized by RU486 in T47D and human endometrial stromal cells (HESC) [13]. In order to further characterize the ability of kaempferol to bind the PR, a molecular docking study was used to highlight and compare the binding interactions of kaempferol with those of RU486, $\mathrm{P}_{4}$, and MPA at active site residues. Kaempferol fits into the ligand binding domain (LBD) and has an affinity score comparable to those of RU486, $\mathrm{P}_{4}$, and MPA (Table 1). Consistent with previous reports, RU486 is a stronger PR binder as compared to $\mathrm{P}_{4}$ and demonstrated the highest affinity score [33]. Top poses of MPA and kaempferol are shown in Figure 1. The 4'-, 5-, and 7-hydroxyl groups of kaempferol form hydrogen bonds with Gln725, Thr894, Asn719, respectively. The binding pose of MPA is very similar to $\mathrm{P}_{4}$ and RU486. In addition to the hydrogen bond between the 3-keto group and the side chain amide moiety of $G \ln 725$, the acetate group in kaempferol extends into the pocket formed by Leu715, Leu718 and Phe794, which is occupied by the 17a-propynyl group in RU486. Kaempferol's interaction with the LBD of PR is driven by a combination of hydrogen bonding and hydrophobic contacts commonly observed for all PR ligands.

\begin{tabular}{|l|l|}
\hline Ligand & Affinity $(\mathbf{k c a l} / \mathbf{m o l})$ \\
\hline Kaempferol & -8.88 \\
\hline$P_{4}$ & -11.76 \\
\hline MPA & -14.36 \\
\hline RU486 & -15.22 \\
\hline
\end{tabular}

Table 1: Known progesterone receptor ligands used in this study and affinity scores for the best docking poses after co-minimization in the binding site

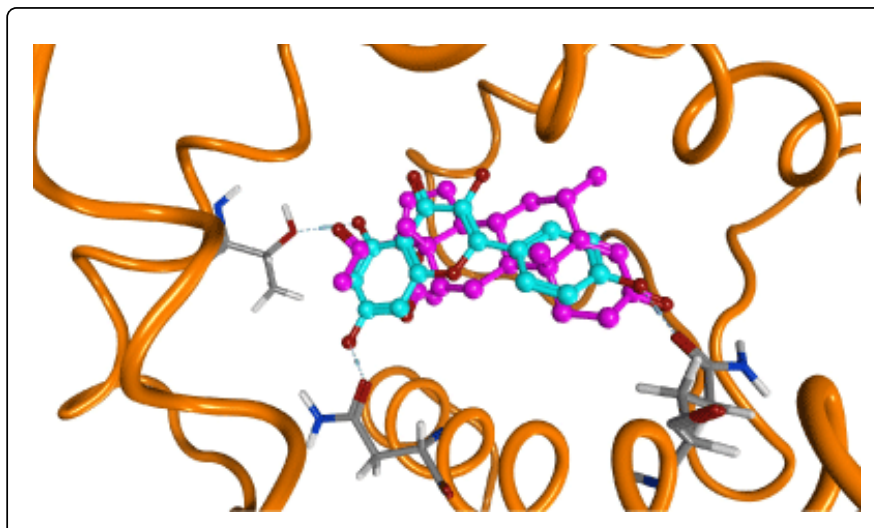

Figure 1: Kaempferol (cyan) and MPA (magenta) bound to the ligand binding domain of PR.

The interactions of the aromatic rings of kaempferol and MPA are similar to $\mathrm{P}_{4}$ in the ligand binding domain of the receptor. The 4'hydroxyl group of kaempferol anchors to Gln725 analogous to the keto group of $\mathrm{P}_{4}$ or MPA. Additionally, the 7-hydroxyl moiety on the phenyl ring forms a hydrogen bond with Asn719 and the 5-hydroxyl group interacts with Thr894. MPA gains more interactions through its ester linked arm that extends into the cavity formed by Leu715, Leu718 and Phe794.

\section{Kaempferol does not increase uterine weight of OVX rats}

Since botanicals are mixtures and are often consumed as multibotanical formulations, the ability of kaempferol to oppose genistein action in the uterus was investigated [34-36]. Genistein is a phytoestrogen found in commonly used botanical supplements soy 
and red clover that activates ER and increases uterine weight and cell proliferation similar to $E_{2}$ [3]. Based on a previous study, SpragueDawley rats $(200 \mathrm{~g})$ fed $375 \mu \mathrm{g}$ genistein/g of food/day demonstrated significant uterine weight gain and proliferation [3].

The dose of genistein and the length of treatment in this study were calculated based on the average amount of food consumed per day (15 $\mathrm{g} /$ animal/day), indicating that genistein at $5.625 \mathrm{mg} / \mathrm{animal} /$ day for 8 days should significantly induce uterine proliferation. Kaempferol's ability to block genistein-induced proliferation in OVX rats after 8 days of oral treatment was investigated (Table 2). As expected, the uterine wet weights of genistein-treated animals were significantly higher than control rats (Table 2). Oral administration of an equal dose of kaempferol (5.625 mg/animal/day) did not significantly increase uterine wet weight compared to control group, indicating that kaempferol did not induce an estrogenic response in the uterus (Table 2 ), consistent with previous reports [37,38]. Additive effects were not observed on uterine weight in animals co-treated with kaempferol and genistein.

\begin{tabular}{|c|c|}
\hline Treatment (5.625mg/animal/day) & Uterine Weight $(\mathbf{m g})$ \\
\hline Vehicle (control) & $63.3 \pm 24$ \\
\hline Genistein & $90.0 \pm 17^{*}$ \\
\hline Kaempferol & $52.0 \pm 25$ \\
\hline Genistein + Kaempferol & $95.7 \pm 22^{*}$ \\
\hline
\end{tabular}

Table 2: Genistein induced uterine wet weight increase in OVX Sprague-Dawley rats. Animals were administered with vehicle control, genistein, kaempferol and geninstein+kaempferol for 8 days via oral gavage. Data are uterine wet weights $(\mathrm{mg}) 24 \mathrm{~h}$ after last treatment (n $=8$ per group $)$. Mean \pm SEM $(* \mathrm{p}<0.05)$ as determined by one-way ANOVA test.

\section{Kaempferol inhibits uterine epithelial cell proliferation}

$\mathrm{P}_{4}$ opposes ER-mediated proliferation in the uterine luminal epithelium, while also preparing the uterine stroma to respond to $\mathrm{E}_{2}$ by inducing stromal proliferation [39-41]. Therefore, the effect of kaempferol, genistein, and the combination on proliferation of rat uterine epithelial cells was investigated. Ki67 staining was utilized to quantify proliferation. Genistein significantly increased luminal epithelial proliferation as compared to control (Figure 2A).

These results are in agreement with previously conducted studies [14]. Kaempferol alone did not increase luminal epithelial proliferation. Importantly, kaempferol when given in combination with genistein decreased proliferation of the uterine luminal epithelial as compared to genistein alone (Figure $2 \mathrm{~A}$ and $2 \mathrm{~B}$ ). Due to minimal proliferation in the stroma, a semi-quantitative assessment method was used to investigate Ki67 expression. Co-administration of kaempferol and genistein stimulated proliferation of uterine stromal cells when compared to the individual treatments and vehicle control (Figure 2C). These changes in luminal and stromal proliferation from co-administration of kaempferol and genistein are consistent with similar studies which assessed actions of $\mathrm{P}_{4}$ in the presence of $\mathrm{E}_{2}$ $[11,42]$.

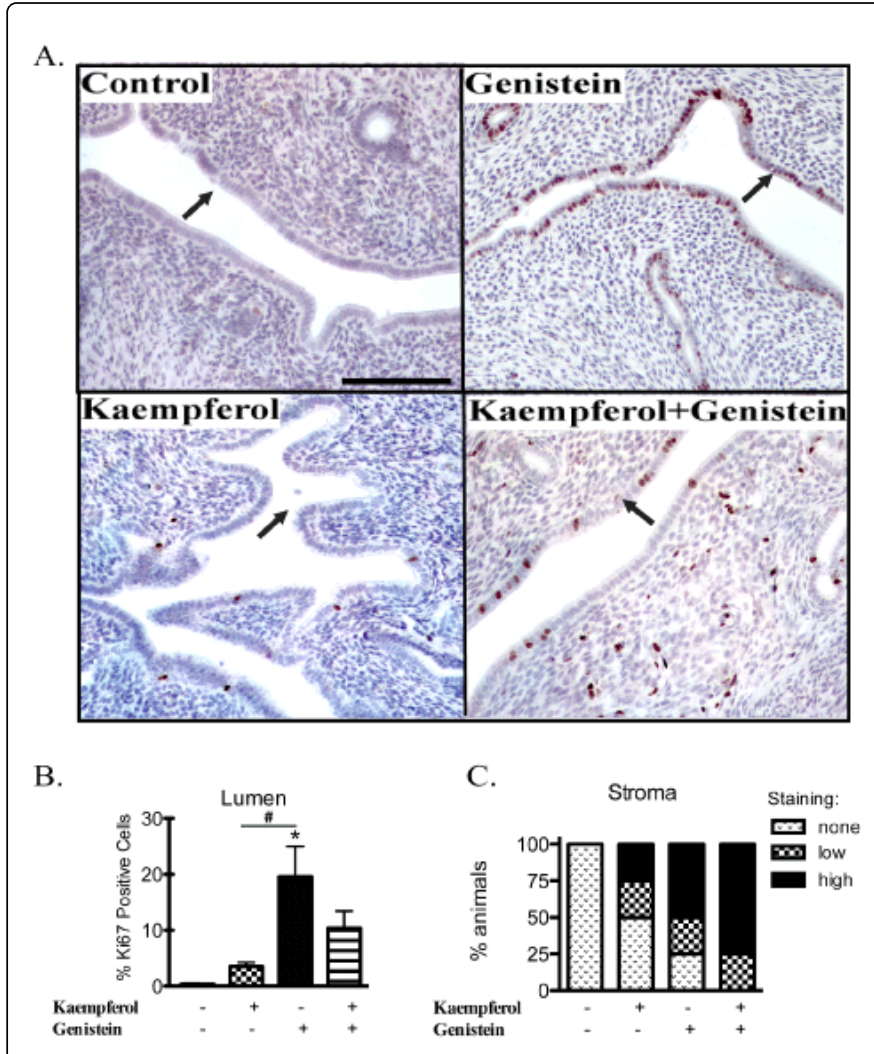

Figure 2: Cell proliferation in response to oral treatment with vehicle (control), genistein, kaempferol and genistein+kaempferol in OVX rat uteri. Representative sections of uterus immunostained for Ki67 (A). Results are represented as percentage of Ki67 positive cells in the luminal epithelium (B). In the stroma, Ki67 staining was categorized as low, medium or high, and shown as percentage of animals from each category $(C)$. Data represented as mean \pm SEM of Ki67 positive cells ( $\mathrm{n}=4$ per group). $* \mathrm{p}<0.05$, significantly different from control, $\# \mathrm{p}<0.05$, significantly different between groups. Scale bar $=100 \mu \mathrm{m}$.

\section{Kaempferol induces $\boldsymbol{A r e g}$ mRNA expression and $\boldsymbol{H a n d} 2$ protein levels in the uterus}

The anti-proliferative action of $\mathrm{P}_{4}$ in the uterine epithelial cells is mediated by Hand 2 induction [4,32]. Immunohistochemistry and qPCR analyses were used to investigate if Hand2 induction correlated with the anti-proliferative effects of kaempferol.

As predicted, an increase in Hand2 expression was observed in uterine stromal cells after kaempferol treatment (Figure 3A). Hand2 protein expression was not induced by genistein, and a slight increase was observed in rats treated with both genistein and kaempferol (Figure 3A). Hand 2 mRNA changes were not observed in any of the treated animals (Figure 3B). The observed discrepancy between Hand2 protein and mRNA expression is likely based on the technique, as immunohistochemistry allows for analysis of specific uterine cell types, whereas the mRNA analyzed was a heterogeneous mixture of all uterine cell types.

Amphiregulin (Areg) is a secreted protein that is induced by $\mathrm{P}_{4}$ in the uterus [43]. Kaempferol treatment significantly induced (5-fold) 
Areg mRNA compared to vehicle treated animals, suggesting that it can function to increase PR-regulated targets in vivo (Figure 3C). Genistein blocked kaempferol-induced Areg expression, consistent with the antagonistic effects of $\mathrm{E}_{2}$ on $\mathrm{P}_{4}$-mediated induction of Areg [43]. Since Areg is a secreted protein, it was not investigated via immunohistochemistry [43].
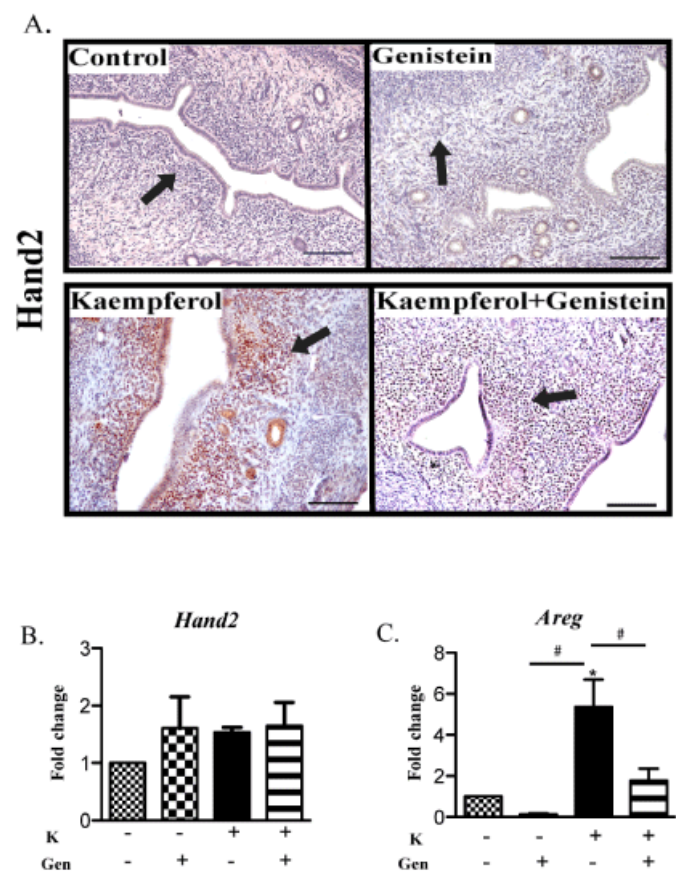

Figure 3: Immunohistochemistry and mRNA expression of $\mathrm{P}_{4}$ targets (Hand 2 and Areg) in the rat uterus after treatment with vehicle control, genistein, kaempferol, and genistein + kaempferol for 8 days. Kaempferol induced expression of Hand2 protein (A) but not mRNA (B), and induced Areg mRNA (C) in the ovariectomized rat uterus. Arrows indicate the uterine stromal compartment. Bar $=100 \mu \mathrm{m}$. qPCR analyses were performed using SYBR technologies. Results were normalized to Rpl1 for Hand2 or Gapdh for Areg. Mean \pm SEM, $* \mathrm{p}<0.05$, significantly different from control, $\# \mathrm{p}<0.05$, significantly different between groups. Scale bar $=100 \mu \mathrm{m}$.

\section{Genistein and kaempferol treatment modulated uterine PR and ERa protein and mRNA expression}

Steroid receptor mRNA and protein levels can be influenced by several physiological factors, including exposure to $\mathrm{E}_{2}$ and $\mathrm{P}_{4}$ [44]. To investigate the effects of genistein and kaempferol on steroid receptor expression in the uterus (the myometrium, endometrial stroma, luminal and glandular epithelium), mRNA levels of ER and PRA were measured. To establish cell type specific PR and ER regulation of steroid receptor expression, protein levels were compared using immunohistochemistry.

$\mathrm{ERa}$ bound to $\mathrm{E}_{2}$ triggers its proteasome-dependent protein degradation $[4,45]$. In order to study ERa regulation, first qPCR for the receptor was performed. ERa mRNA levels in whole uterus were not affected by genistein treatment, but was significantly induced by kaempferol and kaempferol combined with genistein (Figure 4A). To investigate ERa protein expression in the different uterine cell types, immunohistochemical analyses were performed. As expected, genistein downregulated $\mathrm{ER} \alpha$ protein expression (Figure 4B).
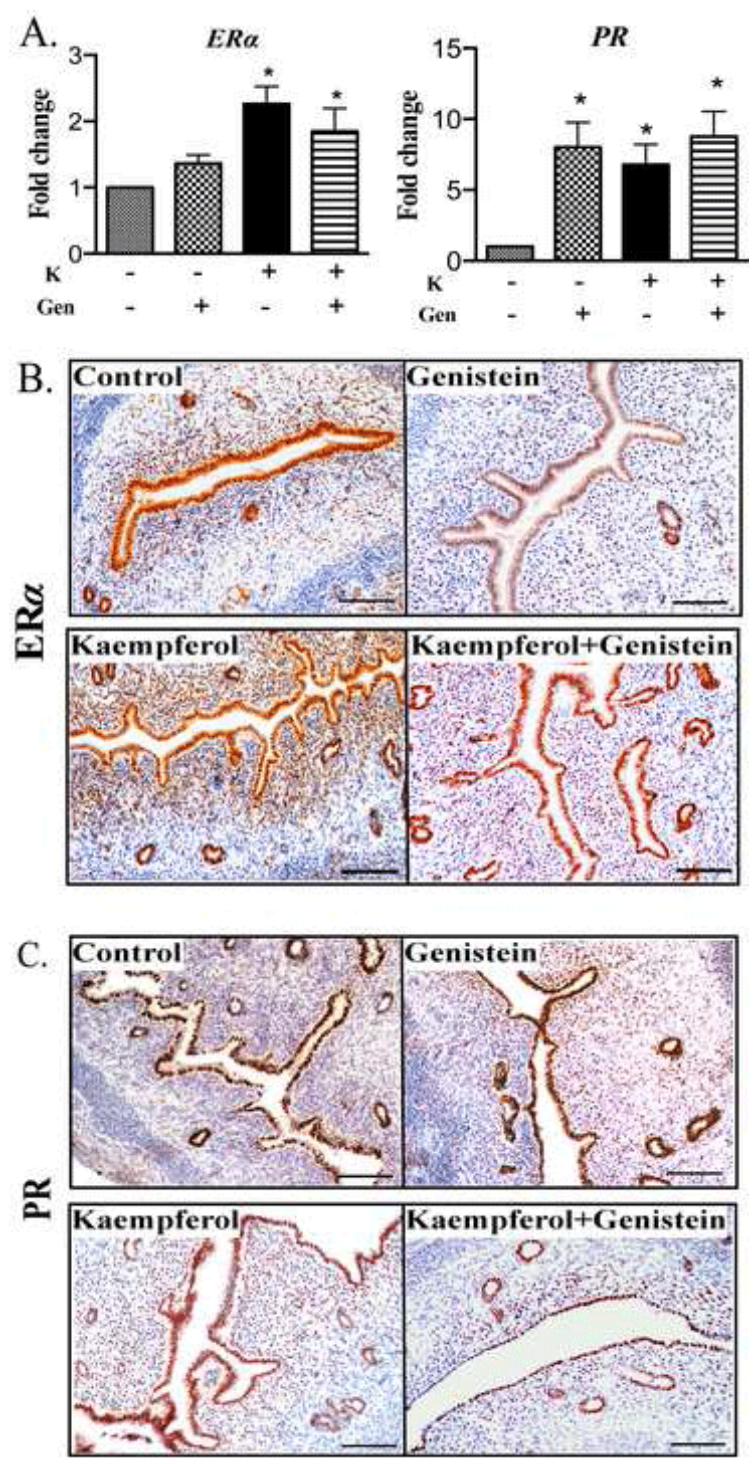

Figure 4: Immunohistochemistry and mRNA expression of ERa and $P R$ in the rat uterus after treatment with vehicle control, genistein, kaempferol, and genistein+kaempferol for 8 days. Kaempferol and genistein differentially regulate $P R$ and $E R a$ mRNA, protein expression, and localization in the uterus. $\mathrm{qPCR}$ analyses were performed using SYBR technologies (A) and uterine sections were stained for ERa (B) and PR (C) expression, $n=8$ per group. Bar $=100 \mu \mathrm{m}$. All results were normalized to RPL1. Mean \pm SEM. $* \mathrm{p}<0.05$, significantly different from control. Groups unmarked were not statistically different from each other.

Interestingly, the induction of $E R \alpha$ mRNA in animals treated with kaempferol alone and in combination group (genistein and kaempferol) was significant and paralleled protein levels (Figure 4A). The lack of uterine weight gain and ERa expression in kaempferol- 
treated rats confirmed that kaempferol did not function as an estrogenic compound.

PR is an ER-regulated target [44]. Genistein treatment significantly increased PR mRNA and protein expression, confirming that genistein acts as a phytoestrogen in rat uteri [46]. Interestingly, kaempferol and kaempferol combined with genistein also significantly upregulated PR mRNA (Figure 4A). PR immunostaining in the vehicle-treated rat uteri was intense and localized to the nucleus throughout the luminal and glandular epithelial cells, but exposure to genistein and kaempferol increased PR expression in the stroma (Figure 4C). Therefore, kaempferol blocked genistein-induced proliferation and induced expression of PR target genes (Areg mRNA and Hand2), which is consistent with kaempferol functioning as a progestin. However, kaempferol acted without stimulating the degradation and loss of PR protein or mRNA expression, which typically occurs when PR binds a ligand (Figure 4C).

\section{Kaempferol, $\mathrm{E}_{2}$ and genistein regulation of $\mathrm{PR}$ expression in human endometrial stromal cells (HESC)}

Upon $\mathrm{P}_{4}$ binding, $\mathrm{PR}$ is targeted for proteasomal degradation, which could be partially responsible for the resistance to progestin therapy observed in endometriotic patients consuming progestins chronically [47].

A.

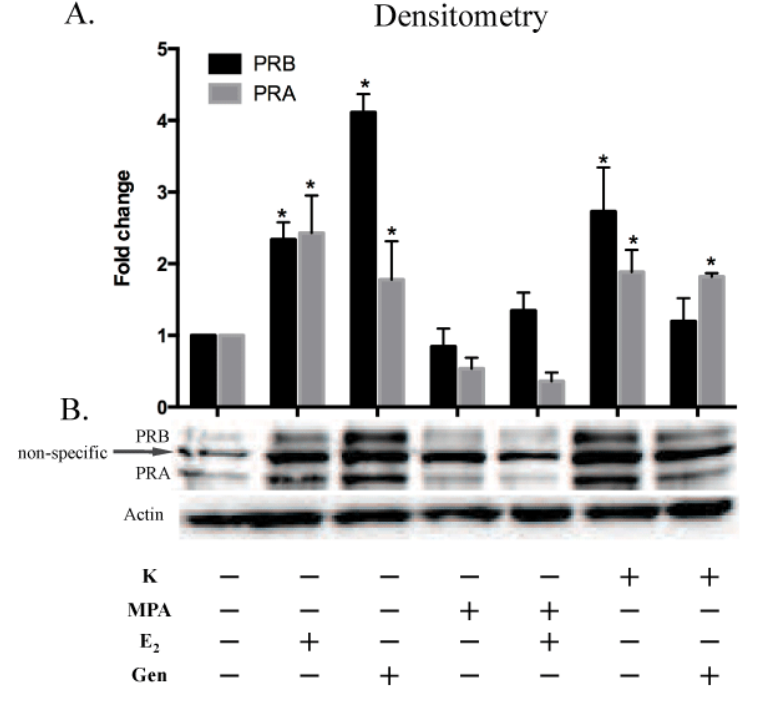

Figure 5: Regulation of PR protein expression in human endometrial stromal cells. Cells were incubated with pure compound for 48 hours. PRA and PRB were induced by $\mathrm{E}_{2}(1 \mu \mathrm{M})$, genistein $(5 \mu \mathrm{M})$ and kaempferol $(20 \mu \mathrm{M})$ as determined by densitometry (A). PR fold change was analyzed using Image-J in triplicate experiments. ${ }^{*} \mathrm{p}<0.05$, indicates significant fold change of PR compared to basal DMSO. MPA $(20 \mu \mathrm{M})$ did not induce PRA and PRB. Membranes were blotted for actin as a loading control (B). Image is a representative blot, experiment repeated in triplicate.

Increased PR expression is mediated by the interaction between ligand-occupied ER with ERE in the PR gene promoter [44]. Since PR mRNA and protein was not reduced in the uteri of kaempferol- stimulated rats and instead actually increased, the regulation of the PR was investigated in vitro. PRA and PRB protein expression was analyzed in HESCs treated with MPA, $\mathrm{P}_{4}$, kaempferol, $\mathrm{E}_{2}$, and genistein (Figure 5). As expected, after a 48-hr treatment with MPA, HESCs had reduced PR protein expression (Figure 5A). HESCs exposed to $\mathrm{E}_{2}$ or genistein had increased $\mathrm{PR}$ protein expression (Figure $5 B)$. The combination treatment of MPA and $E_{2}$ maintained $P R$ expression at basal levels. Similar to the in vivo results in rat uteri, kaempferol increased PR protein expression (Figure 5A and 5B). When combined with genistein treatment, kaempferol decreased genistein-induced PR expression, similar to MPA when combined with $\mathrm{E}_{2}$.

\section{Kaempferol does not induce ERE-luciferase in HESCs}

Enhanced PR protein expression in the uterine stroma from kaempferol treatment in vivo could be due to activation of ER, which in turn transcriptionally induces PR [44]. Although kaempferol was previously reported to function as an ER modulator in HeLa cells, rat primary osteoblasts and human breast cancer MCF-7 cells in a concentration range of 10-70 $\mu \mathrm{M}$ [48-52], the ability of kaempferol to activate the ER in HESCs has not been reported. Therefore, HESCs were treated with a vehicle control, genistein, kaempferol, and genistein combined with kaempferol and ER activation was monitored by ERE-luciferase transcription (Figure 6). $\mathrm{E}_{2}$ and genistein, but not kaempferol significantly induced ERE-luciferase expression in HESCs (Figure 6). In agreement with PR protein expression (Figure 5), genistein $(5 \mu \mathrm{M})$ was as active as $\mathrm{E}_{2}$ at inducing ERE-luciferase transcription (Figure 6). The ER antagonist desmethylarzoxifen (DMA) (100 nM) significantly inhibited $E_{2}$-induced signaling suggesting that these activities are mediated through ER. Despite increased PR protein expression after kaempferol treatment, ERE transcription was not significantly activated (Figure 6).

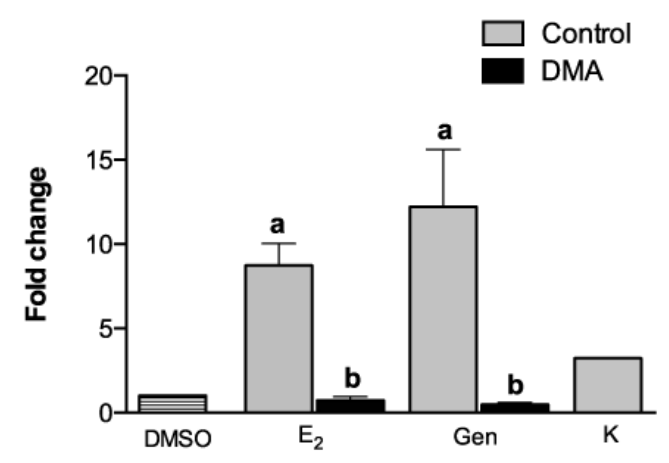

Figure 6: ERE-luciferase induction in human endometrial stromal cells. Endometrial stromal cells were transiently transfected with ERE-luciferase and ERa and treated with pure compounds $\mathrm{E}_{2}(1$ $\mu \mathrm{M})$, genistein $(5 \mu \mathrm{M})$, and kaempferol $(20 \mu \mathrm{M})$ with and without the ER antagonist DMA (100 nM) for 48 hours. Data represent mean fold change \pm SEM of relative light units normalized to $\beta$-gal in triplicate experiments. (a) indicates significant luciferase induction compared to basal DMSO; (b) indicates significant reduction of luciferase induction by DMA as determined by Student's t-Test, $\mathrm{n}=3,{ }^{*} \mathrm{p}<0.05$. 


\section{Kaempferol does not induce PSA-luciferase in MDA-MB-231} cells

MPA is one of the most commonly used synthetic progestins $[8,53]$. Although MPA signals through PR, it also activates other nuclear receptors such as $A R$, thereby increasing side effects and the risk of breast cancer and cardiovascular disorders $[8,54,55]$. Thus, it was important to evaluate if kaempferol also activates AR signaling. As PRE and ARE have similar consensus sequences, it is difficult to accurately determine androgen-specific activity when both $\mathrm{PR}$ and AR are expressed in a cell $[34,56]$. Therefore, in this experiment, MDAMB-231 breast cancer cells, which express AR but not PR, were used. Prostate specific antigen (PSA) is an AR-regulated gene and its proximal promoter is highly responsive to androgens [56,57]. Thus, PSA-luciferase activity was measured in MDA-MB-231 cells to monitor AR activation. As expected, MPA activated PSA-luciferase in MDA-MB-231 cells, verifying that MPA stimulates AR-mediated transcription (Figure 7). In the presence of RU486 (1 $\mu \mathrm{M})$, an AR antagonist, MPA-induced AR signaling was completely inhibited, further demonstrating MPA activation of AR-mediated transcription (Figure 7). Although there was a trend for increased activation with kaempferol, this was not statistically significant.

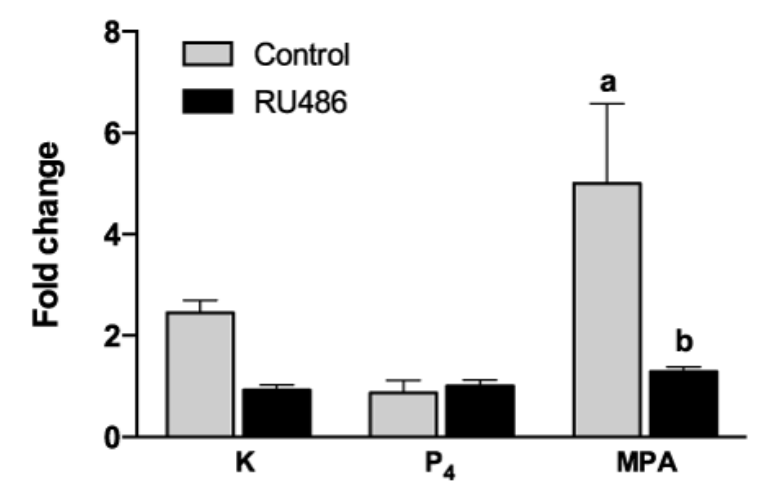

Figure 7: PSA-luciferase induction in MDA-MB-231 cells. MDAMB-231 cells were transiently transfected with PSA-luciferase and treated with pure compounds kaempferol $(20 \mu \mathrm{M}), \mathrm{P}_{4}(1 \mu \mathrm{M})$, and MPA $(1 \mu \mathrm{M}))$ with and without AR antagonist RU486 $(1 \mu \mathrm{M})$ for 48 hours. MPA activates PSA-luciferase and can be antagonized by RU486. Kaempferol and $\mathrm{P}_{4}$ did not significantly activate $A R$ signaling. Data represent mean fold change \pm SEM of relative light units normalized to $\beta$-gal in triplicate experiments. (a) indicates significant luciferase induction compared to basal DMSO; (b) indicates significant reduction of luciferase induction by RU486 as determined by Student's t-Test, ${ }^{*} \mathrm{p}<0.05$.

\section{Discussion}

Many studies have provided evidence that kaempferol may function as progestin, including (i) activation of PR signaling in vitro [13], (ii) antagonistic effects when a potent PR agonist is present [13], (iii) similar anti-inflammatory mechanisms when compared to $\mathrm{P}_{4}[18,20]$ and (iv) protection against ovarian cancer $[22,58,59]$. To date, there are no reports regarding the progestogenic effects of kaempferol in vivo. Therefore, this study investigated the effects of kaempferol on $\mathrm{P}_{4}$ signaling in the uteri of OVX Sprague-Dawley rats and steroid receptor activation in vitro. In this study, the kaempferol treatment of cultured cells and animals were within the range used in previous studies $(10-70 \mu \mathrm{M}$ and $1-100 \mathrm{mg} / \mathrm{kg}$, respectively) $[3,13,18,60,61]$. These findings, together with previous data, collectively suggest that kaempferol may have the potential to provide progestogenic biological activity in vivo, particularly in the uterus.

Computational analysis demonstrated that kaempferol adopts binding poses, which closely mimic the binding conformation and the interactions commonly observed between the LBD of $P R$ and established ligands. The hydrophobic and hydrogen bond interactions of kaempferol are highly analogous to those of the steroid scaffold of $\mathrm{P}_{4}$. In addition to the interactions expected for the steroid-based backbone of MPA, it gains additional interactions with the binding site through its ester-linked appendage, which may be associated with its agonistic effects. Molecular modeling data are consistent with previous in vitro binding analysis performed with kaempferol and the $\mathrm{PR}$ ligand binding domain [13]. Future investigations using additional molecular modeling techniques to study the recruitment of coregulatory proteins are warranted to elucidate the molecular mechanisms of kaempferol as a selective progesterone receptor modulator.

One well-established function of $\mathrm{P}_{4}$ is the inhibition of $\mathrm{E}_{2}$-induced uterine cell proliferation $[1,11]$. As a result, progestins are used therapeutically to reduce the proliferation of $E_{2}$-dependent endometrial cancers and in endometriosis [62]. Kaempferol reduced genistein-induced proliferation in luminal epithelial cells, while preparing the uterine stroma to respond to genistein, leading to stromal cell proliferation. Hand2 mediates the anti-proliferative effects of $\mathrm{P}_{4}$ in the uterus [32]. Although kaempferol treatment stimulated Hand 2 protein expression in the uterine stroma, there was no change in Hand 2 mRNA expression. Hand 2 mRNA and protein expression in kaempferol treated uteri likely do not correlate completely because Hand2 is expressed in a discrete area within the uterine stroma, easily detectable by immunohistochemistry, but constituting only a small portion of the total uterine mRNA. Previous in vivo studies have reported that $\mathrm{P}_{4}$ treatment completely abolished $\mathrm{E}_{2}$-induced proliferation in the uterine epithelium $[39,40]$. Although kaempferol significantly reduced genistein-mediated proliferation in the uterus, it did not completely eliminate proliferation. However, it is important to note that the differences between $\mathrm{P}_{4}$ and kaempferol could be due to different routes of treatment administration (oral vs. subcutaneous), potency, and duration. $\mathrm{P}_{4}$ is poorly orally bioavailable driving the administration of synthetic progestins, like MPA. Since genistein and kaempferol are biologically active in the uterus after oral administration, botanicals (or combination therapies) containing both estrogenic and progestogenic compounds might provide the desired benefits for mitigating menopausal symptoms while also preventing $\mathrm{E}_{2}$-induced uterine hyperplasia.

Reduced PR protein following progestin administration occurs in $\mathrm{P}_{4}$ responsive cell types, and may be used to study progestogenic action within a target tissue $[13,63,64]$. Unexpectedly, the uteri of kaempferol-treated rats maintained expression of $\mathrm{PR}$ in vivo and in HESCs. This finding was especially intriguing because PR induction is linked to estrogenic signaling $[32,35,66]$, which was not observed with kaempferol treatment, in vitro or in vivo as demonstrated by no change in ERE-luciferase expression and a lack of increased uterine weight. While kaempferol has been described as a partial ER agonist in human breast cancer cells and cervical cells $[49,50]$, multiple studies investigating the estrogenic actions of kaempferol in vivo detected no uterotrophic estrogenic effects [37,60], which is further corroborated in this study. Progestin therapy resistance occurs in some populations 
of patients with endometrial cancer and endometriosis due to reduced or loss of PR protein expression after prolonged treatment $[51,67,68]$. Endometrial cancer is the most common gynecological malignancy in the United States and the fifth most common cancer among women in the world $[47,53,69]$. The anti-proliferative effects of kaempferol, without simultaneously downregulating PR expression raises an interesting possibility that a novel therapeutic approach could be attempted using kaempferol as an alternative for longer-term management of endometriotic symptoms.

The mechanism of progestin action is complex and may exert effects other than those traditionally expected from progestogenic activity $[47,70]$. Progestins currently available for prescription, such as MPA, interact with other steroidal receptors, including the AR, mineralocorticoid receptor (MR) and glucocorticoid receptor (GR) $[8,71]$. It has been proposed that AR, GR and MR activity enhance the proliferation of mammary epithelial cells, increasing breast cancer risk $[8,72,73]$. The androgenic nature of MPA has been suggested to be one mechanism through which it may give rise to blot clots, heart attacks and hypertension [6]. Therefore, an ideal progestin would be devoid of non-specific GR, MR, and AR activity $[8,53,74]$. Contrary to MPA, kaempferol did not significantly activate AR in vitro. However, further studies are needed to confirm kaempferol's action on GR and MR.

Taken together, the results from this study demonstrate that kaempferol functions as a progestin in vivo to mediate antiproliferative effects of genistein in the uterus and modulate steroid receptor expression, without activating AR and ER signaling. The notion that phytoprogestins can be identified provides a new type of endocrine modulator, which could interact with and change endocrine signaling. Endocrine disruption is a critical issue as women are already consuming botanical-based therapies for a variety of conditions, such as infertility, menopause, and premenstrual symptoms $[9,75]$. Identification and characterization of progesterone-like molecules from natural sources might allow for informed decisions regarding their use as part of complicated multi-botanical formulations or as an alternative to current progestin therapies.

\section{Acknowledgements}

This work was supported by NIH R21 AT005377-01A1 to (J.E.B.) from the National Center for Complementary and Alternative Medicine (NCCAM) and the Office for Research in Women's Health, UIC University Graduate Fellowship (M.F.T.), and NIH T32 AT007533-01 to (M.P.E.) from the National Center for Complementary and Alternative Medicine (NCCAM) and the Office of the Director. We appreciate the support from the P50 AT00155 UIC/NIH Center for Botanical Dietary Supplements Research sponsored by the Office of Dietary Supplements and the NCCAM for pilot funding.

\section{References}

1. Kim JJ, Sefton EC, Bulun SE (2009) Progesterone receptor action in leiomyoma and endometrial cancer. Prog Mol Biol Transl Sci 87: 53-85.

2. Scarpin KM, Graham JD, Mote PA, Clarke CL (2009) Progesterone action in human tissues: regulation by progesterone receptor (PR) isoform expression, nuclear positioning and coregulator expression. Nucl Recept Signal 7: e009.

3. Santell RC, Chang YC, Nair MG, Helferich WG (1997) Dietary genistein exerts estrogenic effects upon the uterus, mammary gland and the hypothalamic/pituitary axis in rats. J Nutr 127: 263-269.
4. Chwalisz K, Perez MC, Demanno D, Winkel C, Schubert G, et al. (2005) Selective progesterone receptor modulator development and use in the treatment of leiomyomata and endometriosis. Endocr Rev 26: 423-438.

5. Pike MC, Ross RK (2000) Progestins and menopause: epidemiological studies of risks of endometrial and breast cancer. Steroids 65: 659-664.

6. M Meendering JR, Torgrimson BN, Miller NP, Kaplan PF, Minson CT. (2008) Estrogen, medroxyprogesterone acetate, endothelial function, and biomarkers of cardiovascular risk in young women. Am J Physiol Heart Circ Physiol 294: H1630-1637.

7. Li CI, Beaber EF, Tang MT, Porter PL, Daling JR, et al. (2012) Effect of depo-medroxyprogesterone acetate on breast cancer risk among women 20 to 44 years of age. Cancer Res 72: 2028-2035.

8. Ghatge RP, Jacobsen BM, Schittone SA, Horwitz KB (2005) The progestational and androgenic properties of medroxyprogesterone acetate: gene regulatory overlap with dihydrotestosterone in breast cancer cells. Breast Cancer Res 7: R1036-1050.

9. Geller SE, Studee L (2005) Botanical and dietary supplements for menopausal symptoms: what works, what does not. J Womens Health (Larchmt) 14: 634-649.

10. Lee E, Hsu C, Haiman CA, Razavi P, Horn-Ross PL, et al. (2010) Genetic variation in the progesterone receptor gene and risk of endometrial cancer: a haplotype-based approach. Carcinogenesis 31: 1392-1399.

11. Chen B, Pan H, Zhu L, Deng Y, Pollard JW (2005) Progesterone inhibits the estrogen-induced phosphoinositide 3-kinase-->AKT-->GSK-3beta-$>$ cyclin D1-->pRB pathway to block uterine epithelial cell proliferation. Mol Endocrinol 19: 1978-1990

12. Zava DT, Dollbaum CM, Blen M (1998) Estrogen and progestin bioactivity of foods, herbs, and spices. Proc Soc Exp Biol Med 217: 369-378.

13. Toh MF, Sohn J, Chen SN, Yao P, Bolton JL, et al. (2012) Biological characterization of non-steroidal progestins from botanicals used for women's health. Steroids 77: 765-773.

14. Zava DT, Duwe G (1997) Estrogenic and antiproliferative properties of genistein and other flavonoids in human breast cancer cells in vitro. Nutr Cancer 27: 31-40.

15. Zand RS, Jenkins DJ, Diamandis EP (2000) Steroid hormone activity of flavonoids and related compounds. Breast Cancer Res Treat 62: 35-49.

16. Overk CR, Guo J, Chadwick LR, Lantvit DD, Minassi A, et al. (2008) In vivo estrogenic comparisons of Trifolium pratense (red clover) Humulus lupulus (hops), and the pure compounds isoxanthohumol and 8prenylnaringenin. Chem Biol Interact 176: 30-39.

17. Burdette JE, Liu J, Lantvit D, Lim E, Booth N, et al. (2002) Trifolium pratense (red clover) exhibits estrogenic effects in vivo in ovariectomized Sprague-Dawley rats. J Nutr 132: 27-30.

18. Calderón-Montaño JM, Burgos-Morón E, Pérez-Guerrero C, LópezLázaro M (2011) A review on the dietary flavonoid kaempferol. Mini Rev Med Chem 11: 298-344.

19. Kim SK, Kim HJ, Choi SE, Park KH, Choi HK, et al. (2008) Antioxidative and inhibitory activities on nitric oxide (NO) and prostaglandin E2 (COX-2) production of flavonoids from seeds of Prunus tomentosa Thunberg. Arch Pharm Res 31: 424-428.

20. Hämäläinen M, Nieminen R, Vuorela P, Heinonen M, Moilanen E (2007) Anti-inflammatory effects of flavonoids: genistein, kaempferol, quercetin, and daidzein inhibit STAT-1 and NF-kappaB activations, whereas flavone, isorhamnetin, naringenin, and pelargonidin inhibit only NFkappaB activation along with their inhibitory effect on iNOS expression and NO production in activated macrophages. Mediators Inflamm 2007: 45673.

21. McCann SE, Freudenheim JL, Marshall JR, Graham S (2003) Risk of human ovarian cancer is related to dietary intake of selected nutrients, phytochemicals and food groups. J Nutr 133: 1937-1942.

22. Luo H, Jiang BH, King SM, Chen YC (2008) Inhibition of cell growth and VEGF expression in ovarian cancer cells by flavonoids. Nutr Cancer 60: 800-809. 
23. Lukanova A, Kaaks R (2005) Endogenous hormones and ovarian cancer epidemiology and current hypotheses. Cancer Epidemiol Biomarkers Prev 14: 98-107.

24. Risch HA (1998) Hormonal etiology of epithelial ovarian cancer, with a hypothesis concerning the role of androgens and progesterone. J Natl Cancer Inst 90: 1774-1786.

25. Lee JY, Shin JY, Kim HS, Heo JI, Kho YJ, et al. (2012) Effect of combined treatment with progesterone and tamoxifen on the growth and apoptosis of human ovarian cancer cells. Oncol Rep 27: 87-93.

26. Williams SP, Sigler PB (1998) Atomic structure of progesterone complexed with its receptor. Nature 393: 392-396.

27. Stawart DTC (2012) Openeye Scientific Software.

28. Jakalian A, Jack DB, Bayly CI (2002) Fast, efficient generation of highquality atomic charges. AM1-BCC model: II. Parameterization and validation. J Comput Chem 23: 1623-1641.

29. Jones G, Willett P, Glen RC (1995) Molecular recognition of receptor sites using a genetic algorithm with a description of desolvation. J Mol Biol 245: 43-53.

30. Corbeil CR, Williams CI, Labute P (2012) Variability in docking success rates due to dataset preparation. J Comput Aided Mol Des 26: 775-786.

31. King SM, Modi DA, Eddie SL, Burdette JE (2013) Insulin and insulin-like growth factor signaling increases proliferation and hyperplasia of the ovarian surface epithelium and decreases follicular integrity through upregulation of the PI3-kinase pathway. J Ovarian Res 6: 12.

32. Li Q, Kannan A, DeMayo FJ, Lydon JP, Cooke PS, et al. (2011) The antiproliferative action of progesterone in uterine epithelium is mediated by Hand2. Science 331: 912-916.

33. Leonhardt SA, Boonyaratanakornkit V, Edwards DP (2003) Progesterone receptor transcription and non-transcription signaling mechanisms. Steroids 68: 761-770.

34. Petz LN, Ziegler YS, Schultz JR, Kim H, Kemper JK, et al. (2004) Differential regulation of the human progesterone receptor gene through an estrogen response element half site and Sp1 sites. J Steroid Biochem Mol Biol 88: 113-122.

35. Kolodziejczyk-Czepas J (2012) Trifolium species-derived substances and extracts--biological activity and prospects for medicinal applications. J Ethnopharmacol 143: 14-23.

36. Classen-Linke I, Alfer J, Krusche CA, Chwalisz K, Rath W, et al. (2000) Progestins, progesterone receptor modulators, and progesterone antagonists change VEGF release of endometrial cells in culture. Steroids 65: 763-771.

37. Trivedi R, Kumar S, Kumar A, Siddiqui JA, Swarnkar G, et al. (2008) Kaempferol has osteogenic effect in ovariectomized adult SpragueDawley rats. Mol Cell Endocrinol 289: 85-93.

38. Stroheker T, Chagnon MC, Pinnert MF, Berges R, Canivenc-Lavier MC (2003) Estrogenic effects of food wrap packaging xenoestrogens and flavonoids in female Wistar rats: a comparative study. Reprod Toxicol 17: 421-432.

39. Martin L, Das RM, Finn CA (1973) The inhibition by progesterone of uterine epithelial proliferation in the mouse. J Endocrinol 57: 549-554.

40. Das RM, Martin L (1973) Progesterone inhibition of mouse uterine epithelial proliferation. J Endocrinol 59: 205-206.

41. Martin L, Finn CA (1970) Interactions of oestradiol and progestins in the mouse uterus. J Endocrinol 48: 109-115.

42. Franco HL, Jeong JW, Tsai SY, Lydon JP, DeMayo FJ (2008) In vivo analysis of progesterone receptor action in the uterus during embryo implantation. Semin Cell Dev Biol 19: 178-186.

43. Das SK, Chakraborty I, Paria BC, Wang XN, Plowman G, et al. (1995) Amphiregulin is an implantation-specific and progesterone-regulated gene in the mouse uterus. Mol Endocrinol 9: 691-705.

44. Kastner P, Krust A, Turcotte B, Stropp U, Tora L, et al. (1990) Two distinct estrogen-regulated promoters generate transcripts encoding the two functionally different human progesterone receptor forms $\mathrm{A}$ and $\mathrm{B}$. EMBO J 9: 1603-1614.
45. Nephew KP, Long X, Osborne E, Burke KA, Ahluwalia A, et al. (2000) Effect of estradiol on estrogen receptor expression in rat uterine cell types. Biol Reprod 62: 168-177.

46. Overk CR, Yao P, Chadwick LR, Nikolic D, Sun Y, et al. (2005) Comparison of the in vitro estrogenic activities of compounds from hops (Humulus lupulus) and red clover (Trifolium pratense). J Agric Food Chem 53: 6246-6253.

47. Bulun SE, Cheng YH, Yin P, Imir G, Utsunomiya H, et al. (2006) Progesterone resistance in endometriosis: link to failure to metabolize estradiol. Mol Cell Endocrinol 248: 94-103.

48. Mulac-Jericevic B, Conneely OM (2005) Reproductive tissue-selective actions of progesterone receptors. Ernst Schering Res Found Workshop : 19-37.

49. Oh SM, Kim YP, Chung KH (2006) Biphasic effects of kaempferol on the estrogenicity in human breast cancer cells. Arch Pharm Res 29: 354-362.

50. Wang J, Fang F, Huang Z, Wang Y, Wong C (2009) Kaempferol is an estrogen-related receptor alpha and gamma inverse agonist. FEBS Lett 583: 643-647.

51. Mulac-Jericevic B, Conneely OM (2004) Reproductive tissue selective actions of progesterone receptors. Reproduction 128: 139-146.

52. Guo AJ, Choi RC, Zheng KY, Chen VP, Dong TT, et al. (2012) Kaempferol as a flavonoid induces osteoblastic differentiation via estrogen receptor signaling. Chin Med 7: 10.

53. Madauss KP, Grygielko ET, Deng SJ, Sulpizio AC, Stanley TB, et al. (2007) A structural and in vitro characterization of asoprisnil: a selective progesterone receptor modulator. Mol Endocrinol 21: 1066-1081.

54. Whitehead MI, Townsend PT, Gill DK, Collins WP, Campbell S (1980) Absorption and metabolism of oral progesterone. Br Med J 280: 825-827.

55. DuPont MS, Day AJ, Bennett RN, Mellon FA, Kroon PA (2004) Absorption of kaempferol from endive, a source of kaempferol-3glucuronide, in humans. Eur J Clin Nutr 58: 947-954.

56. Cleutjens $\mathrm{KB}$, van Eekelen CC, van der Korput HA, Brinkmann AO, Trapman J (1996) Two androgen response regions cooperate in steroid hormone regulated activity of the prostate-specific antigen promoter. J Biol Chem 271: 6379-6388.

57. Shenk JL, Fisher CJ, Chen SY, Zhou XF, Tillman K, et al. (2001) p53 represses androgen-induced transactivation of prostate-specific antigen by disrupting hAR amino- to carboxyl-terminal interaction. J Biol Chem 276: 38472-38479.

58. Gates MA, Tworoger SS, Hecht JL, De Vivo I, Rosner B, et al. (2007) A prospective study of dietary flavonoid intake and incidence of epithelial ovarian cancer. Int J Cancer 121: 2225-2232.

59. Luo H, Rankin GO, Li Z, Depriest L, Chen YC (2011) Kaempferol induces apoptosis in ovarian cancer cells through activating p53 in the intrinsic pathway. Food Chem 128: 513-519.

60. Breinholt V, Hossaini A, Svendsen GW, Brouwer C, Nielsen E (2000) Estrogenic activity of flavonoids in mice. The importance of estrogen receptor distribution, metabolism and bioavailability. Food Chem Toxicol 38: 555-564.

61. Zhang Q, Zhang Y, Zhang Z, Lu Z (2009) Sensitive determination of kaempferol in rat plasma by high-performance liquid chromatography with chemiluminescence detection and application to a pharmacokinetic study. J Chromatogr B Analyt Technol Biomed Life Sci 877: 3595-3600.

62. Kim JJ, Kurita T, Bulun SE (2013) Progesterone action in endometrial cancer, endometriosis, uterine fibroids, and breast cancer. Endocr Rev 34: 130-162.

63. Sheridan PLP, Evans RMR, Horwitz KBK (1989) Phosphotryptic peptide analysis of human progesterone receptor. New phosphorylated sites formed in nuclei after hormone treatment. J Biol Chem 264: 6520-6528.

64. Lange CA, Shen T, Horwitz KB (2000) Phosphorylation of human progesterone receptors at serine-294 by mitogen-activated protein kinase signals their degradation by the 26 S proteasome. Proc Natl Acad Sci U S A 97: 1032-1037. 
Citation: Toh MF, Mendonca E, Eddie SL, Endsley MP, Lantvit DD, et al. (2014) Kaempferol Exhibits Progestogenic Effects in Ovariectomized Rats. J Steroids Horm Sci 5: 136. doi:10.4172/2157-7536.1000136

Page 10 of 10

65. Hong SH, Nah HY, Lee JY, Gye MC, Kim CH, et al. (2004) Analysis of estrogen-regulated genes in mouse uterus using cDNA microarray and laser capture microdissection. J Endocrinol 181: 157-167.

66. Tibbetts TA, Mendoza-Meneses M, O'Malley BW, Conneely OM (1998) Mutual and intercompartmental regulation of estrogen receptor and progesterone receptor expression in the mouse uterus. Biol Reprod 59: 1143-1152.

67. Zhao SJ, Chen XJ, Feng YJ (2007) [Influence of long-term treatment with MPA on the biological character of endometrial carcinoma Ishikawa cell]. Fen Zi Xi Bao Sheng Wu Xue Bao 40: 103-112.

68. Zhao S, Li G, Yang L, Li H (2013) Response-specific progestin resistance in a newly characterized Ishikawa human endometrial cancer subcell line resulting from long-term exposure to medroxyprogesterone acetate. Oncology letters 5: 139-144.

69. Wang Y, Hanifi-Moghaddam P, Hanekamp EE, Kloosterboer HJ Franken P, et al. (2009) Progesterone inhibition of Wnt/beta-catenin signaling in normal endometrium and endometrial cancer. Clin Cancer Res 15: 5784-5793.
70. Druckmann R (2003) Progestins and their effects on the breast. Maturitas 46 Suppl 1: S59-69.

71. Gompel A (2012) Micronized progesterone and its impact on the endometrium and breast vs. progestogens. Climacteric 15 Suppl 1: 18-25.

72. Sørensen GV, Cronin-Fenton DP, Sørensen HT, Ulrichsen SP, Pedersen L, et al. (2012) Use of glucocorticoids and risk of breast cancer: a Danish population-based case-control study. Breast Cancer Res 14: R21.

73. Leo JC, Guo C, Woon CT, Aw SE, Lin VC (2004) Glucocorticoid and mineralocorticoid cross-talk with progesterone receptor to induce focal adhesion and growth inhibition in breast cancer cells. Endocrinology 145: 1314-1321.

74. Sitruk-Ware R (2004) New progestogens: a review of their effects in perimenopausal and postmenopausal women. Drugs Aging 21: 865-883.

75. Kelly JP, Kaufman DW, Kelley K, Rosenberg L, Anderson TE, et al. (2005) Recent trends in use of herbal and other natural products. Arch Intern Med 165: 281-286. 